\title{
Real-Time Sharing and Following of Continuous Glucose Monitoring Data in Youth
}

John B. Welsh • Mark Derdzinski • Andrew Scott Parker •

Sarah Puhr · Annika Jimenez · Tomas Walker

Received: December 7, 2018 / Published online: January 30, 2019

(C) The Author(s) 2019

\begin{abstract}
Background: Those caring for children and adolescents with diabetes often use glucose concentration and trending information in management decisions. Some continuous glucose monitoring (CGM) systems offer real-time sharing and monitoring capabilities through mobile apps carried by the person with diabetes and the caregiver(s), respectively. Few large studies have explored real-world associations between sharing and following, CGM utilization, and glycemic outcomes.

Methods: We performed a retrospective evaluation of device usage and glycemic control in 15,000 youth ranging in age from 2 to 18 years by analyzing anonymized data that had been uploaded with a mobile app that provides optional sharing. The presence or absence of a real-time monitor (a "Follower") was established on 15 June 2018. Each day with $\geq 1$ uploaded glucose values was counted as a day of device usage. Between-group glucose comparisons were made with two-sided Welch's $t$ tests.
\end{abstract}

Enhanced Digital Features To view enhanced digital features for this article go to https://doi.org/10.6084/ m9.figshare.7604939.

J. B. Welsh $(\bowtie) \cdot$ M. Derdzinski · A. S. Parker ·

S. Puhr · A. Jimenez - T. Walker

Dexcom, Inc., San Diego, CA, USA

e-mail: john.welsh@dexcom.com
Results: Overall, $94.8 \%$ of the population used the sharing feature and had at least one Follower. The mean numbers of Followers for patients aged $2-5,6-12$, and $13-18$ years were $2.8,2.8$, and 2.4 , respectively. In all three age categories, the presence of at least one Follower was associated with lower mean glucose values, more glucose values in the $70-$ to $180-\mathrm{mg} / \mathrm{dL}$ range, correspondingly fewer glucose values representing hypoglycemia and hyperglycemia, and significantly more device utilization.

Conclusion: Real-time sharing and following of CGM data are associated with improved device utilization and glycemic parameters. The observed association suggests either more timely interventions or higher levels of engagement among the caregivers or the youth with diabetes.

Funding: Dexcom, Inc.

Keywords: Adherence; Adolescents; Children; Continuous glucose monitoring; Remote monitoring; Time in range; Type 1 diabetes

\section{INTRODUCTION}

Numerous randomized controlled trials and observational studies have established the value of continuous glucose monitoring (CGM) for people with insulin-requiring diabetes [1], and the technology is endorsed in the pediatric population for effectively lowering hemoglobin 
A1C (A1C), reaching target $\mathrm{A} 1 \mathrm{C}$, reducing glucose variability, and increasing time in range [2]. For parents and others involved in the care of young children with diabetes, the ability to remotely monitor a child's real-time CGM data is generally welcome, especially during regular sleeping hours [3]. The feasibility of remote monitoring of insulin delivery and CGM data were subsequently confirmed in a randomized study [4], which found reductions in nocturnal hypoglycemia that were modest and not statistically significant. A very recent randomized crossover study of parents of children with type 1 diabetes (T1D) [5] confirmed that remote monitoring was associated with improvements in multiple measures of quality of life, reduced family stress, and improved parental sleep.

Current CGM systems provide many parents of children with diabetes the opportunity to unobtrusively follow their child's glucose levels throughout the day. This technology has also led to the rapid accumulation of glucose data in formats that are amenable to retrospective analysis. By examining data from users of a smartphone-based app for CGM data visualization who had the opportunity to share that data in real time, we sought associations between Followers, the extent of device utilization, and the distribution of glucose concentrations.

\section{METHODS}

Anonymized device utilization and glucose concentration data from a convenience sample of 15,000 mobile app users aged 2-18 years that were voluntarily uploaded in the first half of 2018 were analyzed. All data were from a single CGM system (Dexcom G5 Mobile; Dexcom, Inc., San Diego, CA, USA) and transmitted by apps running on either the iOS (Apple, Inc., Cupertino, CA, USA) or the Android (Google LLC, Mountain View, CA, USA) platform. By default, the G5 Mobile app uploads data to the Dexcom Share Cloud and allows users to grant one or more remote monitors ("Followers") with real-time access to their data. Alerts on the Follow app can be configured independently of alerts on the G5 Mobile app. The presence or absence of a Follower was established on 15
June 2018. Each day with at least one valid glucose concentration was counted as a day of device usage. Between-group comparisons were made using two-sided Welch's $t$ tests.

Since this was a retrospective study and all patient identifiers were removed before data analysis was begun, it was not registered as a trial. Data were from patients who had consented to allow use of their anonymized data for research purposes. All procedures followed were in accordance with the ethical standards of the institutional review board and ethics committee on human experimentation (institutional and national) and with the Helsinki Declaration of 1964, as revised in 2013.

\section{RESULTS}

Overall, $94.8 \%$ of the population used the Share feature and had at least one Follower. The mean numbers of Followers for patients aged 2-5, $6-12$, and $13-18$ years were $2.8,2.8$, and 2.4 , respectively. The presence of at least one Follower was consistently associated with lower mean glucose values, more glucose values in the $70-$ to $180-\mathrm{mg} / \mathrm{dL}$ range with correspondingly fewer that were either $<70$ or $>180 \mathrm{mg} / \mathrm{dL}$, and significantly more device utilization (Table 1). The percentages of glucose values representing hypoglycemia of $<55 \mathrm{mg} / \mathrm{dL}$ and hyperglycemia of $>250 \mathrm{mg} / \mathrm{dL}$ were also lower in all three age-specific groups with one or more Followers. By contrast, there were no apparent trends in device utilization or the distribution of glucose values across the three age groups.

\section{DISCUSSION}

Real-time CGM data are valuable for everyone who takes insulin and for those involved in their care. An early study of the nocturnal monitoring of children in a camp setting specialized for children with diabetes [6] showed that remote monitoring significantly improved the rate at which hypoglycemia alarms were responded to. A separate study of users of Nightscout software, which enables CGM data suggested to be monitored, suggested that 
Table 1 Utilization and glycemic outcomes for continuous glucose monitoring users without and with remote real-time monitors (Followers)

\begin{tabular}{|c|c|c|c|}
\hline Metric & Age range (years) & Zero Followers & One or more Followers \\
\hline \multirow[t]{3}{*}{$N(\%)$} & $2-5$ & $76(7.6 \%)$ & $923(92.4 \%)$ \\
\hline & $6-12$ & $330(5.0 \%)$ & $6335(95.0 \%)$ \\
\hline & $13-18$ & $376(5.1 \%)$ & $6960(94.9 \%)$ \\
\hline \multirow[t]{3}{*}{ Adherence (days per week) } & $2-5$ & $4.8(1.8)$ & $6.2(0.7)^{* *}$ \\
\hline & $6-12$ & $4.7(1.9)$ & $6.2(0.7)^{* *}$ \\
\hline & $13-18$ & $4.9(1.6)$ & $5.9(0.9)^{* *}$ \\
\hline \multirow[t]{3}{*}{ Glucose $(\mathrm{mg} / \mathrm{dL})$} & $2-5$ & $188.4(50.8)$ & $187.3(36.8)$ \\
\hline & $6-12$ & $192.6(39.3)$ & $184.2(30.5)^{* *}$ \\
\hline & $13-18$ & $192.6(43.9)$ & $186.5(33.9)^{*}$ \\
\hline \multirow[t]{3}{*}{ Glucose values < $55 \mathrm{mg} / \mathrm{dL}(\%)$} & $2-5$ & $1.4 \%(3.2 \%)$ & $1.0 \%(1.4 \%)$ \\
\hline & $6-12$ & $1.3 \%(3.8 \%)$ & $1.0 \%(1.4 \%)$ \\
\hline & $13-18$ & $1.5 \%(2.6 \%)$ & $1.1 \%(1.5 \%)^{*}$ \\
\hline \multirow[t]{3}{*}{ Glucose values $<70$ mg/dL (\%) } & $2-5$ & $4.1 \%(6.1 \%)$ & $3.2 \%(3.7 \%)$ \\
\hline & $6-12$ & $3.4 \%(5.0 \%)$ & $3.1 \%(3.0 \%)$ \\
\hline & $13-18$ & $4.0 \%(4.9 \%)$ & $3.2 \%(3.1 \%)^{*}$ \\
\hline \multirow[t]{3}{*}{ Glucose values $70-180 \mathrm{mg} / \mathrm{dL}(\%)$} & $2-5$ & $48.5 \%(21.8 \%)$ & $49.6 \%(16.6 \%)$ \\
\hline & $6-12$ & $46.5 \%(19.9 \%)$ & $51.0 \%(14.7 \%)^{* *}$ \\
\hline & $13-18$ & $46.5 \%(20.4 \%)$ & $49.8 \%(16.2 \%)^{*}$ \\
\hline \multirow[t]{3}{*}{ Glucose values > $180 \mathrm{mg} / \mathrm{dL}(\%)$} & $2-5$ & $47.4 \%(24.9 \%)$ & $47.2 \%(18.4 \%)$ \\
\hline & $6-12$ & $50.1 \%(21.1 \%)$ & $45.9 \%(15.9 \%)^{* *}$ \\
\hline & $13-18$ & $49.5 \%(22.0 \%)$ & $47.0 \%(17.3 \%)$ \\
\hline \multirow[t]{3}{*}{ Glucose values $>250 \mathrm{mg} / \mathrm{dL}(\%)$} & $2-5$ & $24.2 \%(19.1 \%)$ & $21.9 \%(14.5 \%)$ \\
\hline & $6-12$ & $23.9 \%(16.9 \%)$ & $20.0 \%(12.3 \%)^{* *}$ \\
\hline & $13-18$ & $24.5 \%(18.6 \%)$ & $20.7 \%(14.0 \%)^{* *}$ \\
\hline
\end{tabular}

Values are presented as the mean with the standard deviation in parenthesis

${ }^{*},{ }^{* *}$ Significant difference between 0 and $\geq 1$ Followers at ${ }^{*} p<0.01 ;{ }^{* *} p<0.001$

remote monitoring contributed to improved quality of life in caregivers [7], and a more recent crossover trial of remote monitoring [5] found that it improved multiple measures of quality of life, reduced family stress, and improved parental sleep. All three studies suggest that much of the popularity and sustained use of this feature is driven by parents and caregivers.

Differences in favor of those having a remote monitor may be attributable to management decisions made by the Follower; for example, parents of a very young children offering carbohydrates in response to impending hypoglycemia. The incremental benefits of having 
multiple Followers were examined in an earlier study of children aged 2-10 [8], where each additional Follower beyond zero was associated with higher device utilization and fewer glucose values of $<70 \mathrm{mg} / \mathrm{dL}$. In older children, the shared data may form the basis of discussions regarding self-care behaviors, whereas adolescents progressing towards full autonomy may still benefit from having at least one other person with real-time access to their CGM data. For unknown reasons, a small minority of those with the ability to share their data had no Followers. This population may include children whose parents have not yet enabled the Following function on their devices or adolescents who vacillate between viewing the system as a best friend or as a spy [9]. Patients who switched to other methods or devices for glucose monitoring before 15 June 2018 are also included in this small group.

Data from the T1D Exchange clinic registry [10] show that CGM use has increased sharply in recent years, with about $28 \%$ of participants using CGM in 2016-2018 compared to only 7\% in 2010-2012. The increases were especially dramatic in youth, with more than eightfold increases in children and adolescents up to age 17 years. The reasons for this increase may include better insurance coverage, which contributes to sustained use of the devices [11], improvements in accuracy and usability of the devices, relaxation of the requirements for periodic blood glucose monitoring, or the increasing popularity of automated insulin delivery systems. Added functionality of the devices-specifically, the availability to share and remotely follow CGM data-may also be contributing to more individuals using the devices and to individual decisions to use them more consistently [12].

The study has several limitations. Most importantly, there were no data on treatment regimens or therapeutic interventions resulting from the remotely monitored CGM data. Secondly, the observational design of the study does not allow for assertions of causality; it may be the case that a confounding variable, such as patient or parental engagement, influences device utilization, the distribution of glucose values, and the likelihood of using the Follow feature. Thirdly, the study design did not allow for any assessment of the "dose effect" of having multiple Followers or of having Followers for different periods of time.

\section{CONCLUSIONS}

In this retrospective analysis of real-world data from young users of CGM, over 94\% of those with the potential to share their data in real time with at least one other person did so. The manner and extent to which the data were used were likely heterogeneous and warrant further study. However, this analysis is one of the first to associate real-time sharing and remote monitoring of CGM data with improved device utilization and glycemic parameters.

\section{ACKNOWLEDGEMENTS}

We thank the participants of the study for allowing their anonymized data to be used.

Funding. This study was funded by Dexcom, Inc. Article processing charges were also provided by Dexcom, Inc. All authors had full access to all of the data in this study and take complete responsibility for the integrity of the data and accuracy of the data analysis.

Authorship. All named authors meet the International Committee of Medical Journal Editors (ICMJE) criteria for authorship for this article, take responsibility for the integrity of the work as a whole, and have given their approval for this version to be published.

Disclosures. John B. Welsh is an employee and shareholder of Dexcom, Inc. Mark Derdzinski is an employee and shareholder of Dexcom, Inc. Andrew Scott Parker is an employee and shareholder of Dexcom, Inc. Sarah Puhr is an employee and shareholder of Dexcom, Inc. Annika Jimenez is an employee and shareholder of Dexcom, Inc. Tomas Walkeris is an employee and shareholder of Dexcom, Inc. 
Compliance with Ethics Guidelines. Since this was a retrospective study and all patient identifiers were removed before data analysis was begun, it was not registered as a trial. Data were from patients who had consented to use of their anonymized data for research purposes. All procedures followed were in accordance with the ethical standards of the institutional review board and ethics committee on human experimentation (institutional and national) and with the Helsinki Declaration of 1964, as revised in 2013.

Data Availability. The datasets analyzed for the current study are available from the corresponding author on reasonable request.

Open Access. This article is distributed under the terms of the Creative Commons Attribution-NonCommercial 4.0 International License (http://creativecommons.org/licenses/ by-nc/4.0/), which permits any noncommercial use, distribution, and reproduction in any medium, provided you give appropriate credit to the original author(s) and the source, provide a link to the Creative Commons license, and indicate if changes were made.

\section{REFERENCES}

1. Welsh JB. Role of continuous glucose monitoring in insulin-requiring patients with diabetes. Diabetes Technol Ther. 2018;20:S242-9.

2. Sherr JL, Tauschmann M, Battelino T, et al. ISPAD clinical practice consensus guidelines 2018: diabetes technologies. Pediatr Diabetes. 2018;19(Suppl 27):302-25.

3. Kaiserman K, Buckingham BA, Prakasam G, et al. Acceptability and utility of the mySentry remote glucose monitoring system. J Diabetes Sci Technol. 2013;7:356-61.
4. Oron T, Farfel A, Muller I, et al. A remote monitoring system for artificial pancreas support is safe, reliable, and user friendly. Diabetes Technol Ther. 2014;16:699-705.

5. Burckhardt MA, Roberts A, Smith GJ, Abraham MB, Davis EA, Jones TW. The use of continuous glucose monitoring with remote monitoring improves psychosocial measures in parents of children with type 1 diabetes: a randomized crossover trial. Diabetes Care. 2018;41:2641-3.

6. DeSalvo DJ, Keith-Hynes P, Peyser T, et al. Remote glucose monitoring in camp setting reduces the risk of prolonged nocturnal hypoglycemia. Diabetes Technol Ther. 2014;16:1-7.

7. Lee JM, Newman MW, Gebremariam A, et al. Realworld use and self-reported health outcomes of a patient-designed do-it-yourself mobile technology system for diabetes: lessons for mobile health. Diabetes Technol Ther. 2017;19:209-19.

8. Parker A, Welsh J, Jimenez A, Graham C. Effects of sharing continuous glucose monitoring (CGM) data from young children with diabetes on CGM usage and hypoglycemic exposure. Pediatr Diabetes. 2017;18:76-7.

9. Messer LH, Johnson R, Driscoll KA, Jones J. Best friend or spy: a qualitative meta-synthesis on the impact of continuous glucose monitoring on life with Type 1 diabetes. Diabet Med. 2018;35:409-18.

10. Foster NC, Beck RW, Miller KM, et al. State of type 1 diabetes management and outcomes from the T1D Exchange in 2016-2018. Diabetes Technol Ther. 2019. https://doi.org/10.1089/dia.2018.0384.

11. Prahalad P, Addala A, Buckingham B, Wilson DM, Maahs DM. Sustained continuous glucose monitor use in low-income youth with type 1 diabetes following insurance coverage supports expansion of continuous glucose monitor coverage for all. Diabetes Technol Ther. 2018;20:632-4.

12. Barley RC, Berget C, DiMeglio LA, Driscoll KA, Hood KK, Buckingham B. Rates of adherence in young children using CGM with remote monitoring. Pediatr Diabetes. 2018;19:84. 